\title{
Público com baixa visão: recomendações para o desenvolvimento de materiais didáticos
}

\section{Low Vision Public: recommendations for development of didactic materials}

Juliana Bueno, Caroline Rodrigues de Lima, Karina de Abreu Antoniolli

baixa visão, acessibilidade, recomendações

A baixa visão pode ser abordada educacionalmente, em Centros de Atendimento Educacional Especializado (CAEEs). Para tanto, docentes que atuam nos CAEEs confeccionam materiais didáticos para estimulação visual dos discentes. Neste contexto, o projeto de pesquisa "Tela Multitoque para Auxílio ao Atendimento Especializado de Pessoas com Baixa Visão: uma experiência centrada no humano" visa adaptar materiais didáticos feitos manualmente em CAEEs para o contexto digital, em parceria com o CAEE Natalie Barraga. Para tal, o projeto pauta-se na metodologia de design centrado no humano da IDEO (2015), que possui 3 etapas: Inspiração, Ideação e Implementação. Neste artigo, apresenta-se um recorte da segunda etapa (Ideação), que na qual ancorada no levantamento feito na primeira etapa, propõe como um dos desdobramentos do projeto um conjunto de recomendações de design para materiais didáticos impressos para baixa visão. O referido conjunto traz 5 categorias de recomendações (cor e contraste, textura, tipografia, leiaute e acabamento) baseadas em revisão de literatura específica acerca do tema.

low vision, accessibility, recommendations

Low vision can be approached educationally, in Specialized Educational Assistance Centers. To this end, teachers who work in these Centers manually prepare didactic materials for the visual stimulation of students. In this context, the research project "Multitouch Screen to Aid Specialized Assistance for People with Low Vision: a human-centered experience" aims to adapt didactic materials made manually in these centers to the digital context, in partnership with Specialized Educational Assistance Center Natalie Barraga. For such, the project is guided by IDEO's human-centered design methodology (2015), which has 3 stages: Inspiration, Ideation and Implementation. This article presents an excerpt from the second stage (Ideation), which, based on gathering done in the first stage, proposes as a development of the project a set of design recommendations for printed educational materials for low vision. The referred set contains 5 categories of recommendations (color and contrast, texture, typography, layout and finishing) based on a specific literature review on the topic.

\section{Introdução}

No âmbito das pessoas que têm algum tipo de deficiência, a deficiência visual é a que tem maior incidência nos contextos mundial e brasileiro. Assim, no Brasil, a deficiência visual atinge cerca de $3,5 \%$ da população, o que abrange aproximadamente 6,5 milhões de pessoas e destas, 6.056.654 apresentam baixa visão (IBGE, 2010).

Anais do $10^{\circ} \mathrm{CIDI}$ e $10^{\circ} \mathrm{CONGIC}$

Kelli C.A.S. Smythe, Rafael de Castro Andrade (orgs.)

Sociedade Brasileira de Design da Informação - SBDI

Curitiba | Brasil | 2021
Proceedings of the $10^{\text {th }} \mathrm{CIDI}$ and $10^{\text {th }} \mathrm{CONGIC}$

Kelli C.A.S. Smythe, Rafael de Castro Andrade (orgs.)

Sociedade Brasileira de Design da Informação - SBDI Curitiba | Brazil | 2021 
O indivíduo com baixa visão (ou visão subnormal) possui comprometimento da função visual, mas ainda assim possui uma visão útil (Amiralian, 2004). Quanto mais cedo for o diagnóstico da baixa visão, mais rapidamente providências médicas, educacionais e sociais podem ser aplicadas no cotidiano desse indivíduo, servindo de auxílio em suas atividades (Domingues et al., 2010).

A Sociedade Brasileira de Visão Subnormal (S.d) afirma que não só as crianças, mas sim as pessoas de maneira geral com baixa visão necessitam de estímulos visuais e de aparelhos auxiliares para realizar as tarefas do dia a dia, ajudando na sua interação e inserção na sociedade. Assim, atividades e programas de reeducação visual são importantes para estimular o pouco de visão que essas pessoas com baixa visão possuem, assim como para ajudar na independência das mesmas.

Por este motivo, de acordo com a Política Nacional de Educação Especial na Perspectiva da Educação Inclusiva (MEC, 2008), as pessoas com baixa visão devem ser atendidas em Centros de Atendimento Educacional Especializados (CAEEs), que são responsáveis pela organização e disponibilização de recursos e serviços pedagógicos e de acessibilidade para atendimento às necessidades educacionais específicas. Ainda, o trabalho dos CAEEs é realizado em conjunto com professores do ensino regular, promovendo os apoios necessários à participação e aprendizagem destes estudantes.

A pessoa com baixa visão no CAEE é inserida em um programa de estimulação visual, onde passa a ter acesso a várias atividades com o objetivo de estimular sua visão residual baseadas nos preceitos de Barraga (1985). Para isso, muitas vezes são utilizados recursos específicos e materiais com base na necessidade de cada indivíduo, a grande parte destes materiais didáticos (ou pranchas de estimulação) é elaborada artesanalmente pelas próprias docentes.

Vale salientar que, os aspectos visuais empregados pelas docentes na elaboração destes artefatos gráficos voltados à eficiência visual estão intrinsecamente ligados a fundamentos de Design como: cor, contraste, leiaute e tipografia (Petterson, 2002; Leborg, 2015; Lupton e Phillips, 2008; Samara, 2014). Embora, tais profissionais não possuam capacitação específica para fazer uso mais eficiente de princípios de Design nos materiais elaborados.

Para a SBDI (2020), "o Design da Informação é uma área do Design cujo propósito é a definição, planejamento e configuração do conteúdo de uma mensagem e dos ambientes em que ela é apresentada, com a intenção de satisfazer as necessidades informacionais dos destinatários pretendidos e de promover eficiência comunicativa". Entretanto, uma investigação preliminar mostrou que não há pesquisas de Design da Informação acerca destas pranchas de estimulação, nem como possibilitar a melhoria das mesmas em aspectos de comunicação, interação ou acessibilidade.

Neste sentido, o projeto de pesquisa "Tela Multitoque para Auxílio ao Atendimento Especializado de Pessoas com Baixa Visão: uma experiência centrada no humano" tem como objetivo adaptar os materiais didáticos que hoje são feitos manualmente nos CAEEs, para o contexto de interação digital, visando uma maior eficiência e replicabilidade destes materiais. 
Com a perspectiva de o projeto ser centrado no humano, prevê-se que o mesmo ocorra em cocriação com docentes e discentes atendidos no CAEE Natalie Barraga, localizado em Curitiba e parceiro do projeto. Assim, a metodologia empregada é a desenvolvida pela IDEO (2015), a qual se divide em 3 etapas: inspiração, ideação e implementação.

Este artigo traz um recorte da segunda etapa, Ideação, na qual depois de levantamento preliminar in loco dos materiais artesanais (registro fotográfico, catalogação e análise gráfica) e entrevistas com as docentes do CAEE Natalie Barraga (Antoniolli \& Bueno, 2020a; 2020b) somados a uma revisão de literatura (todos insumos levantados na etapa Inspiração), propõe como um dos resultados do projeto um conjunto de recomendações de Design para o desenvolvimento de materiais didáticos impressos voltados ao público de baixa visão. Estas recomendações subsidiarão não somente o projeto de pesquisa aqui apresentado, como se entende que elas podem trazer contribuição substancial para o desenvolvimento de materiais gráfico-informacionais em geral, que visem ser acessíveis ao público de baixa visão.

Assim, o artigo é estruturado em: fundamentação teórica, metodologia utilizada, resultados alcançados (recomendações) e, por fim, considerações finais.

\section{Fundamentação teórica}

Para uma maior compreensão do que será apresentado nos resultados deste artigo, se faz necessário trazer o referencial teórico sobre a definição e desdobramentos da baixa visão, estimulação visual e fundamentos de design.

\section{Baixa visão}

A baixa visão (BV) também chamada de visão subnormal é uma deficiência visual que compromete a função visual do indivíduo mesmo após tratamento e correção refrativa, mas não o impede de realizar tarefas (OMS).

Marta Gil (2000), refere-se a BV como a alteração da capacidade funcional uma vez que provoca reduções significativas da acuidade visual, do campo visual e da sensibilidade ao contraste, além da limitação de outras capacidades. Assim, necessita ser auxiliado por recursos que melhorem sua resolução visual (SBVSN, 2010). Em contexto pedagógico, devese considerar as características individuais de cada pessoa com baixa visão, pois mesmo que apresente o mesmo grau de acuidade visual, pode diferir quanto ao seu desempenho funcional (Domingues, 2010). Como Lima (2018) menciona, a qualidade da visão interfere nos potenciais visuais que devem ser explorados e nos recursos utilizados.

Neste sentido, para entender melhor a necessidade deste público, é válido apresentar as causas que provocam a baixa visão e suas principais consequências. Bruno e Mota (2001) classificam as causas como congênitas ou adquiridas. Dentre as mais frequentes, Lima (2018) menciona que as responsáveis pela redução do campo visual periférico são: Toxoplasmose Ocular Congênita; Degeneração Macular Relacionada à Idade; Doença de Stargardt. Pela redução do campo visual central, estão: Glaucoma; Retinose Pigmentar. Pelo aparecimento de 
projeções e manchas escuras na visão, estão: Retinopatia da Prematuridade; Retinopatia Diabética. Já em casos de imagens desfocadas e com pouca nitidez: Albinismo e Catarata Congênita. Por fim, respectivamente, por alteração nas fibras do nervo óptico e oscilação ocular: Atrofia no Nervo Óptico e Nistagmo Congênito. A Figura 1 traz uma simulação dos principais tipos de baixa visão.

Figuras 1: Simulação dos principais acometimentos devido à baixa visão (redução do campo visual periférico e central, manchas e perda de nitidez). Fonte: as autoras.

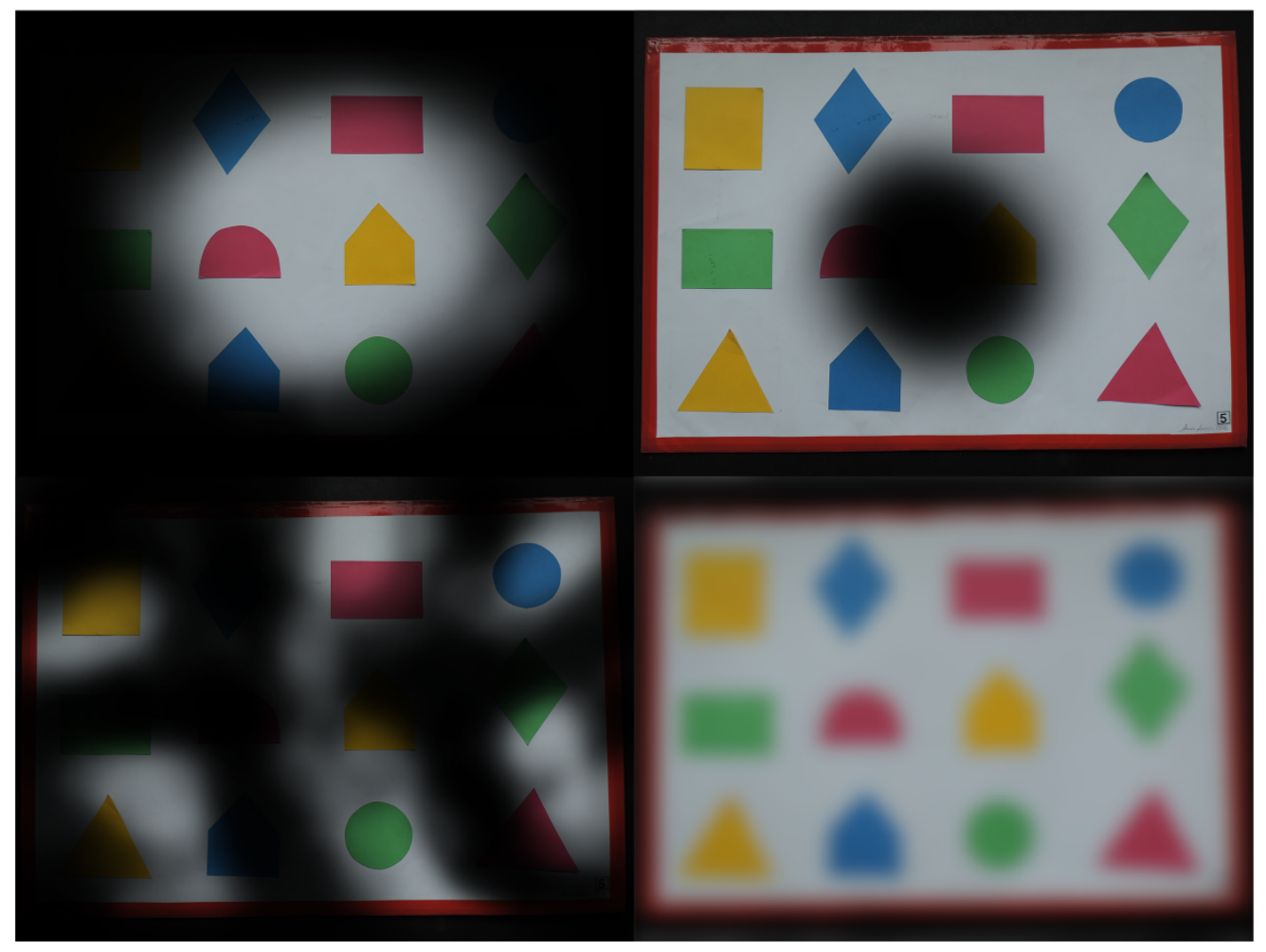

Além das consequências citadas, Domingues (2010) acrescenta que o indivíduo com baixa visão pode apresentar dificuldade de enxergar de perto e/ou de longe, dificuldade na percepção de contrastes e cores, sensibilidade à luz e outros. Assim, a pessoa com baixa visão encontra-se em uma posição intermediária entre a realidade das pessoas que enxergam normalmente e a dos deficientes visuais totais, no caso, os cegos (Kulpa et al., 2010).

\section{Estimulação Visual}

Com a constatação de que pessoas diferentes com o mesmo grau de acuidade visual possuem uma distinção no desempenho visual e a indicação de que há uma necessidade em relacionar o aproveitamento máximo da visão residual de uma criança com seu potencial de aprendizagem, pesquisadoras como Barraga (1985) passaram a salientar o quão importante são avaliações funcionais, sendo formas de avaliar criteriosamente a capacidade $\mathrm{e}$ desempenho visual de uma criança.

Barraga (1970), ao trabalhar na área de Educação Especial, especificamente com Deficiência Visual, percebeu que quando aplicava atividades para crianças consideradas cegas 
que as mesmas ainda utilizavam a visão restante para realizar seus estudos e práticas da vida diária (Bruno, 2005). Natalie Barraga, como citado por Piñero et al. (2003), afirmou que a partir de estímulos adequados à capacidade visual de cada indivíduo consegue-se melhorar sua eficiência visual. A autora, desta forma, publicou a Escala de Deficiência Visual (Escala de Deficiência Visual, 1970; WHO, 1992).

Conforme Barraga (1985), a função visual é dividida em três grupos:

- $1{ }^{\text {a }}$ Função Visual: sendo as funções ópticas (habilidades visuais; reação; fixação; e seguimento visual);

- $\quad 2^{\mathrm{a}}$ Função Visual: sendo as funções ópticas e perceptivas (habilidades visuais; coordenação olho-mão-objeto; manipulação de objetos; exploração visual do ambiente; reconhecimento e identificação; associação; e memória visual);

- $3^{\text {a }}$ Função Visual: considerando funções ópticas, perceptivas e visomotoras (habilidades visuais; coordenação visomotora; percepção; constância perceptual; relações espaciais; análise e síntese visual).

Tendo como base as colocações expostas, e tendo em vista principalmente a terceira função visual, pesquisadores como Frostig desenvolveram materiais, como o Programa de Percepção Visual (Frostig et al., 1992). Com o propósito de direcionar aqueles profissionais que trabalham com a reeducação visual de indivíduos com baixa visão.

- Seção 1, itens 1 a 12: discriminação de formas geométricas, contorno de objetos, intensidade claro-escuro, tamanho e posição;

- Seção 2, itens 13 a 24: discriminação de tamanho, detalhes de objetos e figuras abstratas, posição no espaço, constância de forma e detalhes de padrões e objetos;

- Seção 3, itens 25 a 36: encaixe visual, perspectiva espacial, discriminação de detalhes em figuras abstratas e objetos;

- Seção 4, itens 37 a 48: discriminação de tamanho, posição, sequência e relações entre letras, palavras, símbolos e grupos de símbolos.

A figura 2 traz exemplos de materiais que são desenvolvidos artesanalmente nos CAEEs para exercícios de pareamento e justaposição com os discentes com baixa visão. 
Figura 2. Materiais confeccionados por docentes nos CAEEs para estimulação visual. Fonte: as autoras.
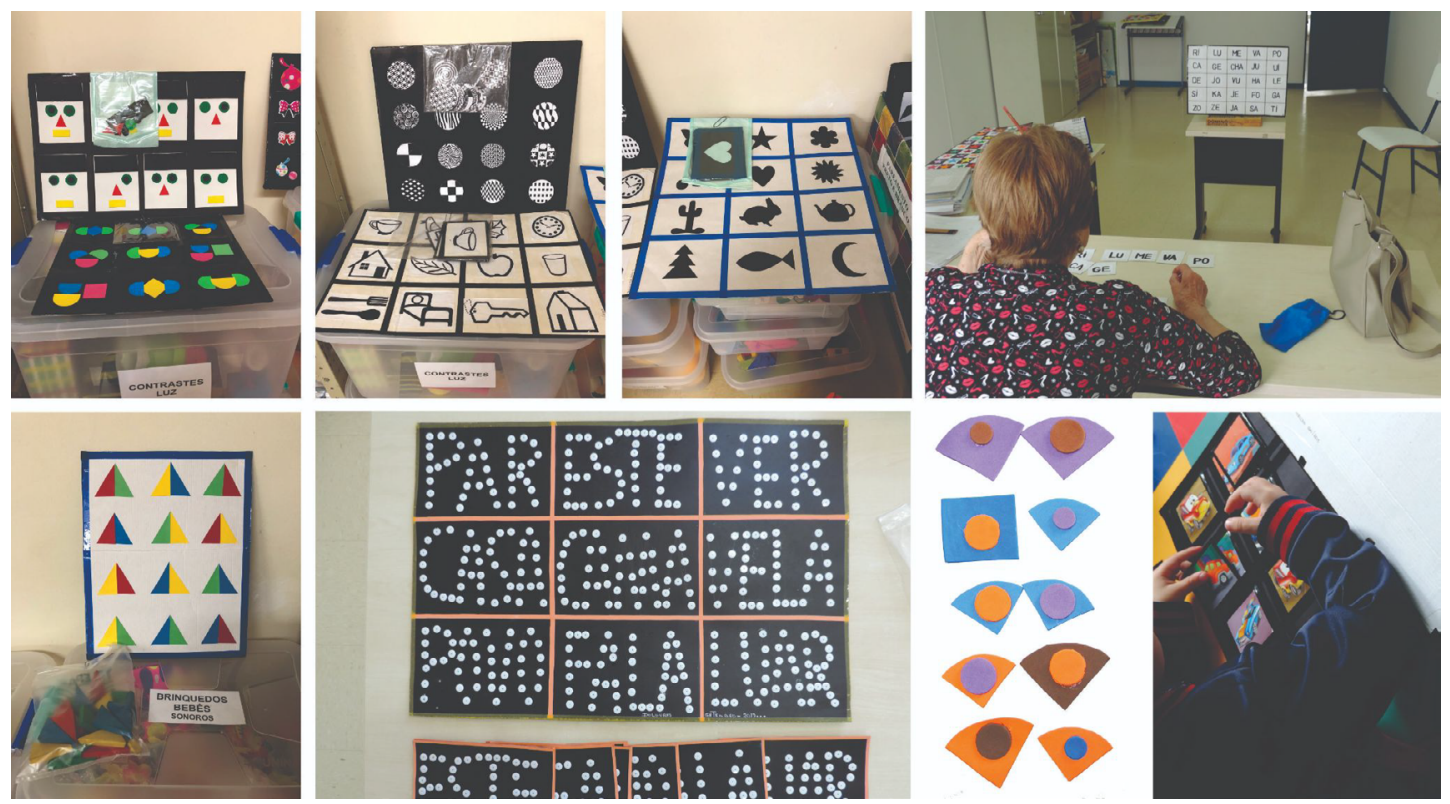

\section{Fundamentos de Design e baixa visão}

Neste artigo entende-se que, as pranchas de estimulação, expostas na seção anterior e que hoje são confeccionadas artesanalmente pelos docentes dos CAEEs podem ser analisadas como representações gráficas. Já que para Engelhardt (2002), uma representação gráfica seria um artefato visível em uma superfície razoavelmente plana, criado com o objetivo de expressar informação. Assim, estas pranchas podem ser analisadas pelos elementos visuais.

\section{Cor e contraste}

As cores são definidas por Leborg (2015) como diferentes comprimentos de onda de luz, percebidas pelos olhos e decodificas pelo cérebro (Guimarães, 2004). Além disso, considerada também como uma ferramenta da comunicação (Petterson, 2002; Samara, 2014), ela é capaz de diferenciar e conectar, ressaltar ou esconder algo (Farina, 2006; Lupton \& Phillips, 2008).

Um dos elementos que contribui com a diferenciação causada pela cor é o contraste, que segundo Wong (1998) refere-se a um tipo de comparação em que diferenças podem ser percebidas. Conforme o autor, a utilização do contraste pode estar presente na relação de elementos visuais e relacionais, podendo ser classificado como contraste de formato, tamanho, cor, textura, direção, posição, espaço ou gravidade. Segundo Itten (1970) o contraste tonal ou contraste entre claro e escuro é o mais eficiente entre os tipos possíveis de contraste.

\section{Textura}

A textura é uma estrutura que pode ser vista e sentida, ela pode ser formada por linhas estruturais e por objetos. As texturas estão presentes nos materiais e podem ser criadas através de inscrição ou aplicação (Leborg, 2015). 


\section{Tipografia}

Farias (2016, p.10) define a tipografia como o "conjunto de práticas e processos envolvidos na criação e utilização de símbolos visíveis relacionados aos caracteres ortográficos (letras) e para-ortográficos (números, sinais de pontuação, etc) para fins de reprodução". Cada uma das letras é considerada uma unidade de informação que combinada de modo significativo com outras, produz palavras e sentenças (Bringhurst, 2018; Lupton, 2014).

\section{Leiaute}

É o arranjo dos elementos de um projeto em relação ao espaço que ocupam e de acordo com um esquema estético geral. Assim, ele consiste na organização dos elementos, sejam eles visuais ou textuais, em um espaço (Ambrose\& Harris, 2011).

\section{Acabamento}

Permite a experiência sensorial do indivíduo com o material impresso. Ele consiste nos processos realizados que darão o toque final a uma peça de design, após o momento que o substrato foi impresso. Dentre eles incluem corte e vinco, encadernação, técnicas de impressão especiais, laminados, vernizes, dobradura, bloqueio de folha e serigrafia (Ambrose \& Harris, 2008).

\section{Metodologia}

A perspectiva de se trabalhar com o Design Centrado no Humano $(\mathrm{DCH})$ é porque ele incorpora as mesmas abordagens do centrado no usuário (DCU), adicionando uma profunda pesquisa de comportamento e um processo iterativo. Ele está direcionado às necessidades de todos os indivíduos. Leva em conta a idade, as habilidades, o contexto social e cultural. Design Inclusivo e Design Universal estão atrelados ao DCH e a acessibilidade está acima de fatores estéticos e econômicos (Visocky O'Grady, 2017).

Por isso, o desenvolvimento deste projeto de pesquisa baseia-se na metodologia da IDEO (2015) para DCH, composta por três etapas: Inspiração, Ideação e implementação.

- Inspiração: propõe-se a entender e observar o usuário para quem se projeta, buscando compreender seus desejos, anseios e necessidades.

- Ideação (foco deste artigo): é classificada como "Criar". Nessa segunda etapa, todas as informações e os dados coletados na primeira etapa passam por um processo de síntese e interpretação, buscando através disso, identificar insights e levantar oportunidades de criação. Sendo assim, é necessário analisar e entender os dados coletados, levantar padrões, definir oportunidades e criar soluções.

- Implementação: tem o propósito principal de viabilizar as melhores ideias e soluções encontradas na segunda etapa, objetivando o lançamento (IDEO, 2015).

A figura 3 expõe visualmente a metodologia empregada. 
Figura 3. Metodologia do DCH. Fonte: as autoras, baseado em IDEO, 2015.

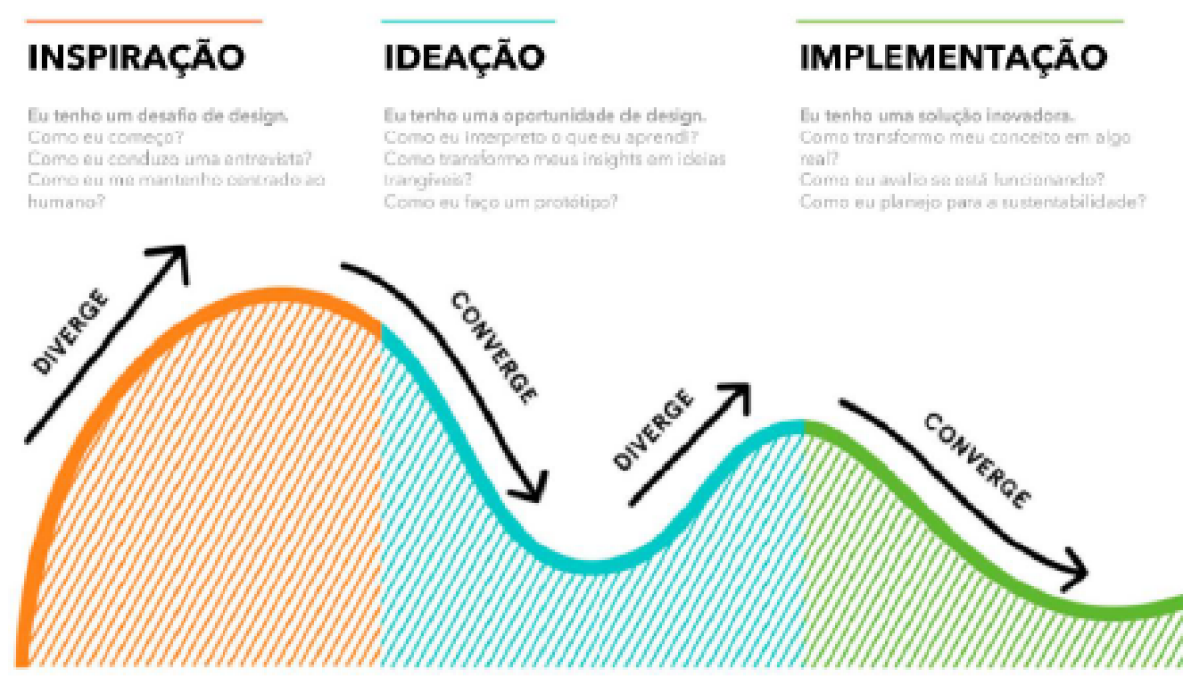

\section{Procedimentos}

A partir do que foi coletado na primeira etapa de Inspiração do projeto (registro fotográfico de 400 pranchas, catalogação por tipo de função, análise gráfica e entrevista contextual com as docentes do CAEE parceiro), passou-se então para o refinamento na etapa de Ideação, uma das atividades previstas era a categorização prévia de recomendações de design para o desenvolvimento de materiais didáticos para o público de baixa visão.

Os resultados trazidos a seguir se baseiam em uma revisão na literatura sobre cor, contraste e textura, como também, sobre tipografia, organização do leiaute e acabamento, em conjunto com o que guias e pesquisas científicas trazem como consideração às necessidades do público com baixa visão.

\section{Resultados}

A partir da leitura dos materiais levantados, foram elencados 6 materiais base para propor o conjunto de recomendações para o público de baixa visão. Estes materiais foram revisados, recomendações semelhantes foram agrupadas e definiu-se 5 categorias de recomendações: Cor e contraste (Quadro 1), Textura (Quadro 2), Tipografia (Quadro 3), Leiaute (Quadro 4) e Acabamento (Quadro 5).

Quadro 1: Recomendações para a adaptação de materiais para pessoas com baixa visão - Cor e Contraste

\begin{tabular}{|l|l|}
\hline Cor e contraste & Fonte \\
\hline Utilizar alto contraste entre o primeiro plano e o plano de fundo. & Arditi (2002) \\
\hline $\begin{array}{l}\text { Evitar a utilização de cores com luminosidades semelhantes, como por } \\
\text { exemplo, vermelho e verde. }\end{array}$ & Arditi (2002) \\
\hline
\end{tabular}


Combinar cores escuras de tons azul, violeta, roxo e vermelho com cores claras de tons verde-azulado, verde, amarelo e laranja. Como por exemplo, combinar roxo mais escuro com verde mais claro.

Evitar a combinação de tons adjacentes do círculo cromático, como por exemplo, laranja e amarelo.

Arditi (2002)

Quadro 2: Recomendações para a adaptação de materiais para pessoas com baixa visão - Textura

\begin{tabular}{|l|l|}
\hline Textura & Fonte \\
\hline $\begin{array}{l}\text { Associar os sentidos tátil e visual nos materiais através da exploração de } \\
\text { texturas simples e complexas (com maior contraste). }\end{array}$ & Lima (2018) \\
\hline Produzir alto relevo através de acabamentos gráficos. & Lima (2018) \\
\hline
\end{tabular}

Quadro 3: Recomendações para a adaptação de materiais para pessoas com baixa visão - Tipografia

\begin{tabular}{|l|l|}
\hline Tipografia & Fonte \\
\hline $\begin{array}{l}\text { O tamanho mínimo da fonte recomendado é 14pt, porém para impressos } \\
\text { ampliados usar de 16pt a 24pt, com base na necessidade do usuário. }\end{array}$ & $\begin{array}{l}\text { UKKAF (2012); Lima (2018); } \\
\text { Domingues (2010) }\end{array}$ \\
\hline $\begin{array}{l}\text { Priorizar o uso de fontes sem serifas com letras legíveis, distinguíveis e } \\
\text { desenho simples como: Arial, Verdana,Trebuchet, APHont, Antique Olive, } \\
\text { Tahoma, Verdana e Helvetica. }\end{array}$ & $\begin{array}{l}\text { UKKAF (2012); Lima (2018); } \\
\text { (2002); APH (2011) }\end{array}$ \\
\hline $\begin{array}{l}\text { Evitar fontes decorativas, complexas e cursivas, somente para gerar } \\
\text { ênfase. }\end{array}$ & Arditi (2002) \\
\hline $\begin{array}{l}\text { Utilizar fontes regulares (maiúsculas e minúsculas), evitando o uso de } \\
\text { blocos de capitulares, itálicos, oblíquos e tipos condensados. }\end{array}$ & $\begin{array}{l}\text { UKKAF (2012); Arditi (2002); } \\
\text { APH (2011) }\end{array}$ \\
\hline $\begin{array}{l}\text { Evitar o uso de somente letras maiúsculas ou em bold para grandes } \\
\text { quantidades de texto. }\end{array}$ & APH (2011) \\
\hline $\begin{array}{l}\text { Não utilizar sublinhados, se necessário dar ênfase, o mais recomendado, } \\
\text { neste caso, é o uso da fonte em bold. }\end{array}$ & UKKAF (2012) \\
\hline $\begin{array}{l}\text { Verificar se há alto contraste entre o texto e fundo. } \\
\text { do corpo de texto em números de página, notas de rodapé, subscritos, } \\
\text { sobrescritos e legendas de imagens. }\end{array}$ & UKKAF (2012), Arditi (2002) \\
\hline $\begin{array}{l}\text { Não utilizar tamanho de texto menor do que o recomendado (14pt) em } \\
\text { Unuma parte do documento. Deve-se usar o mesmo tamanho da fonte }\end{array}$ & UKKAF (2012 \\
\hline
\end{tabular}

Quadro 4: Recomendações para a adaptação de materiais para pessoas com baixa visão - Leiaute

\begin{tabular}{|l|l|}
\hline Leiaute & Fonte \\
\hline Utilizar margens largas de encadernação. & Arditi (2002), UKKAF (2012) \\
\hline Recuar 1 polegada $(2,54 \mathrm{~cm})$ nas margens. & APH (2011) \\
\hline $\begin{array}{l}\text { Criar um layout consistente, para isso utilizar grids como guias para } \\
\text { posicionar títulos e imagens, estabelecer margens, altura da coluna de } \\
\text { texto, largura da medianiz, posição da numeração e colocação de } \\
\text { cabeçalhos e rodapés. }\end{array}$ & UKKAF (2012) \\
\hline
\end{tabular}




\begin{tabular}{|c|c|}
\hline Alinhar o texto à esquerda e não o justificar à direita. & UKKAF (2012); APH (2011) \\
\hline $\begin{array}{l}\text { Diferenciar os vários níveis de hierarquia da informação (níveis dos títulos, } \\
\text { corpo de texto e das legendas) e manter consistente em todo o } \\
\text { documento. A utilização de texto em negrito, texto ampliado e } \\
\text { espaçamento de linha auxiliam nessa organização. }\end{array}$ & UKKAF (2012) \\
\hline Não colocar imagens à esquerda de um texto. & UKKAF (2012) \\
\hline $\begin{array}{l}\text { Não dividir em duas linhas informações como nomes, números de } \\
\text { telefone, datas, códigos postais, medidas e unidades de medidas. }\end{array}$ & UKKAF (2012) \\
\hline $\begin{array}{l}\text { Evitar o recuo do texto no início de parágrafos, exceto em listas } \\
\text { numeradas ou com marcadores. Para diferenciar dois parágrafos, deve-se } \\
\text { deixar um espaço entre eles. }\end{array}$ & UKKAF (2012); APH (2011) \\
\hline $\begin{array}{l}\text { Utilizar espaços duplos entre parágrafos ou outros corpos de textos (e.g } \\
\text { 30-34pt). }\end{array}$ & APH (2011) \\
\hline Utilizar espaço de 1.25 entre as linhas. & APH (2011) \\
\hline Utilizar a entrelinha de 25 a $30 \%$ do corpo da fonte. & Arditi (2002) \\
\hline $\begin{array}{l}\text { Utilizar no máximo } 62 \text { caracteres por linha para impressões com fontes } \\
\text { menores. Em caso de textos ampliados, usar aproximadamente } 39 \\
\text { caracteres por linha. }\end{array}$ & APH (2011) \\
\hline Manter o texto na horizontal, inclusive em tabelas, diagramas e mapas. & UKKAF (2012) \\
\hline $\begin{array}{l}\text { Conectar visualmente itens relacionados. Se necessário, utilizar linhas } \\
\text { pontilhadas e linhas de células em tabelas. }\end{array}$ & UKKAF (2012) \\
\hline Evitar linhas órfãs e viúvas. & UKKAF (2012) \\
\hline $\begin{array}{l}\text { Reduzir ou eliminar o uso de colunas conforme a ampliação do texto. Para } \\
\text { uma melhor distinção de colunas, deixar um espaço adequado entre elas, } \\
\text { se necessário acrescentar uma linha divisória vertical. }\end{array}$ & UKKAF (2012) \\
\hline Inserir numeração de páginas para facilitar a navegação. & UKKAF (2012) \\
\hline $\begin{array}{l}\text { Em caso de adaptação de textos e livros, inserir a numeração do texto } \\
\text { original, como também a nova numeração, podendo ser incluída em } \\
\text { colchetes ou na parte superior ou inferior do arquivo. }\end{array}$ & UKKAF (2012) \\
\hline $\begin{array}{l}\text { Organizar o sumário e sempre atualizá-lo se houver adição de informação, } \\
\text { e também informar tanto o número da página do texto original como o do } \\
\text { arquivo adaptado. }\end{array}$ & UKKAF (2012) \\
\hline $\begin{array}{l}\text { Incluir um rodapé com informações adicionais, como títulos de seções } \\
\text { e/ou capítulos. }\end{array}$ & UKKAF (2012) \\
\hline Utilizar elementos que auxiliem na navegação, como setas. & UKKAF (2012) \\
\hline
\end{tabular}

Quadro 5: Recomendações para a adaptação de materiais para pessoas com baixa visão - Acabamento

\begin{tabular}{|l|l|}
\hline Acabamento & Fonte \\
\hline Evitar a utilização de capas e papéis com acabamentos brilhantes. & UKKAF (2012); Arditi (2002) \\
\hline $\begin{array}{l}\text { Imprimir o documento em papel de cor clara como branco, marfim, creme, } \\
\text { amarelo pastel ou papel rosa. }\end{array}$ & APH (2011); \\
\hline
\end{tabular}




\begin{tabular}{|l|l|}
\hline $\begin{array}{l}\text { Utilizar papéis com acabamento fosco, espesso e opaco, com gramatura } \\
\text { de } 80 \mathrm{~g} / \mathrm{m}^{2}, \text { preferencialmente o de } 100 \mathrm{~g} / \mathrm{m}^{2}, \text { pois não é reflexivo e evita } \\
\text { que o texto do verso seja visível. }\end{array}$ & UKKAF (2012); Arditi (2002) \\
\hline $\begin{array}{l}\text { Utilizar documentos no formato padrão A4 em retrato, se necessário, usar } \\
\text { o formato paisagem ou A3 para inserir a largura total de uma tabela, } \\
\text { diagrama ou mapa inteiro. }\end{array}$ & UKKAF (2012) \\
\hline Encadernar o documento de modo que fique plano. & UKKAF (2012) \\
\hline $\begin{array}{l}\text { Diferenciar livros e documentos através de tamanhos, cores e formatos } \\
\text { variados. }\end{array}$ & Arditi (2002) \\
\hline Utilizar pautas de cadernos escurecidas e mais largas. & Lima (2018) \\
\hline
\end{tabular}

Considera-se que este conjunto de recomendações, para além do projeto de pesquisa aqui citado no artigo, serve de insumo para todo e qualquer projeto gráfico-informacional que tenha como premissa ser acessível ao público de baixa visão. Especialmente, novos materiais artesanais que precisem, ainda ser elaborados pelos CAEEs.

Prevê-se, ainda, em etapa posterior, classificar quais destas se recomendações se aplicam também para materiais didáticos digitais para o público de baixa visão e que tais informações sejam publicadas em um guia com exemplificações visuais, para auxiliar designers, docentes e familiares na elaboração de materiais didáticos acessíveis ao público aqui descrito.

\section{Considerações Finais}

Pessoas com baixa visão necessitam de um trabalho específico de estimulação visual, o qual se pauta nos preceitos de Barraga (1985) e pela perspectiva da educação inclusiva no Brasil, hoje é oferecido em Centros de Atendimento Educacional Especializados, os CAEEs. Hoje, os materiais didáticos (pranchas de estimulação) elaborados nos CAEEs são feitos de maneira artesanal pelos profissionais que lá trabalham.

Um projeto de pesquisa, pautado no Design Centrado no Humano prevê transformar estas pranchas de estimulação em materiais digitais e interativos, seguindo três etapas: Inspiração, Ideação e Implementação. Neste sentido, a primeira etapa do projeto, Inspiração, teve um trabalho focado em pesquisa in loco, registro e catalogação dos materiais didáticos elaborados no CAEE Natalie Barraga (instituição parceira) e uma extensa revisão de literatura acerca de baixa visão e recomendações de design para este público.

Já na etapa Ideação, os insumos coletados na primeira foram compilados para se tornarem insights. Um dos resultados desta etapa foi o recorte exposto neste artigo, onde a partir de matérias pertinentes foi levantado um conjunto preliminar de recomendações para o desenvolvimento de materiais didáticos impressos para o público de baixa visão. Vislumbra-se que as recomendações aqui expostas podem ser aplicadas em outros materiais gráficoinformacionais que almejam ser acessíveis ao público de baixa visão.

Como pesquisas futuras, prevê-se uma categorização destas recomendações que podem ser aplicadas também ao contexto digital (no sentido de serem aplicadas no projeto de 
pesquisa) e um guia para auxiliar designers, docentes e familiares na elaboração de materiais didáticos acessíveis a pessoas com baixa visão.

\section{Referências}

Ambrose, G., \& Harris, P. (2011). Basic Design 02 Layout (2 ed.). Singapore: AVA Publishing.

Ambrose, G., \& Harris, P. (2008). The Production Manual.Lausanne: AVA PublishingAS.

Amiralian, M. L.T. M. (2004). Sou cego ou enxergo? As questões da baixa visão. Educar, n. 23, 15 - 28. Curitiba: Editora UFPR.

Antoniolli, K. A., \& Bueno, J. (2020a).Tela Multitoque para Auxílio ao Atendimento Especializado de Pessoas com Baixa Visão: uma experiência centrada no humano: etapa 1 - análise preliminar de materiais. Anais do XII Simpósio de Pesquisa e Iniciação Científica do UNICURITIBA. Curitiba (PR), UNICURITIBA. Recuperado de https//www.even3.com.br/anais/spic2020/294669-TELA-MULTITOQUE-PARA-AUXILIO-AOATENDIMENTO-ESPECIALIZADO-DE-PESSOAS-COM-BAIXA-VISAO--UMAEXPERIENCIA-CENTRADA-NO

Antoniolli, K. A., \& Bueno, J. (2020b). Tela Multitoque para Auxílio ao Atendimento Especializado de Pessoas com Baixa Visão: uma experiência centrada no humano: etapa 1 - contexto do usuário. Anais do XII Simpósio de Pesquisa e Iniciação Científica do UNICURITIBA. Curitiba (PR), UNICURITIBA. Recuperado de https//www.even3.com.br/anais/spic2020/294671-TELA-MULTITOQUE-PARA-AUXILIO-AOATENDIMENTO-ESPECIALIZADO-DE-PESSOAS-COM-BAIXA-VISAO--UMAEXPERIENCIA-CENTRADA-NO

Arditi, A. (2002). Designing for People with Partial Sight: Making Text Legible. [S. I.]: Lighthouse International.

Arditi, A. (2002). Effective Color Contrast: Designing for People with Partial Sight and Color Deficiencies. [S.I.]: Lighthouse International.

Barraga, N. (1970). Visual Efficiency Scale. Louisville, KY: American Printing House for the Blind.

Barraga, N. (1985). Disminuidos visuales y aprendizaje (enfoque evolutivo). Madrid, ES: Organización Nacional de Ciegos de Espana.

Brasil. (2004). Decreto $n^{\circ}$ 5.296, de 2 de dezembro de 2004. Capítulo II, Art. 5. [S. I.]. Recuperado de http://www.planalto.gov.br/ccivil_03/_ato2004-2006/2004/decreto/d5296.htm

Bringhurst, R. (2018). Elementos do Estilo Tipográfico. 4. ed. São Paulo: Ubu Editora.

Bruno, M. M. G. (2005). A inclusão da criança com baixa visão e múltipla na educação infantil. Anais do Congresso da Sociedade Brasileira de Visão Subnormal.

Bruno, M.M.G., \&Mota, M.G.B. (2001). Programa de Capacitação de Recursos Humanos do Ensino Fundamental: deficiência visual vol. 1 fascículos I - II - III. Brasília, DF: Ministério da Educação, Secretaria de Educação Especial. Recuperado de http://portal.mec.gov.br/seesp/arquivos/pdf/def_visual_1.pdf

Domingues, C. A. et.al. (2010). A educação especial na perspectiva da inclusão escolar: os alunos com deficiência visual: baixa visão e cegueira. Brasília: MEC, SEE; [Fortaleza]: UFC. 
Engelhardt, Y. (2002). The language of graphics: a framework for the analysis of syntax and meaning in maps, charts and diagrams. Amsterdam: ILLC Publications.

Farias, P. L. (2016). Estudos sobre tipografia: letras, memória gráfica e paisagens tipográficas. Tese (Livre Docência em Design) - Faculdade de Arquitetura e Urbanismo, Universidade de São Paulo, São Paulo.doi:10.11606/T.16.2017.tde-10032017-161946.

Farina, M. (2006). Psicodinâmica das cores em comunicação. 5.ed. São Paulo: Edgard Blucher.

Ferroni, M. C. C., \& Gasparetto, M. E. R. F. (2012). Escolares com baixa visão: percepção sobre as dificuldades visuais, opinião sobre as relações com comunidade escolar e o uso de recursos de tecnologia assistiva nas atividades cotidianas. Revista Brasileira de Educação Especial, [s. I.], 18(2), 301 - 318. doi: 10.1590/S1413-65382012000200009

Frostig, M., Horne, D., \& Miller, A-M. (1992). Las destrezas perceptuales y los retos enel aprendizaje de lalectura y la escritura. Una guía para laexploración y comprensión de dificultades específicas. Revista Actualidades Investigativas em Educación.

Gagliardo, H. G. R. G., \& Nobre, M. I. R. S. (2001). Intervenção Precoce na Criança com Baixa Visão. Revista Neurociências, [s. I.],9(1), 16 - 19. Recuperado de <http://www.revistaneurociencias.com.br/edicoes/2001/RN\%2009\%2001/Pages\%20from \%2 0RN\%2009\%2001-5.pdf

Guimarães, L. (2004). A cor como informação: a construção biofísica, linguística e cultural da simbologia das cores. 3. ed. São Paulo: Annablume.

Fraser, T., \& Banks, A. (2007). O guia completo da cor. 2.ed. São Paulo: Senac São Paulo.

Ideo.org. (2015). The Field Guide to Human-Centered Design. 1. ed. Recuperado de https://www.designkit.org/resources/1

Itten, J. (1970). The Elements of Color. Nova York: Van Nostrand Reinhold.

KITCHEL, E. (2011). APH Guidelines for Print Document Design. Recuperado de https://www.aph.org/aph-guidelines-for-print-document-design/

Kulpa, C. C., Teixeira, F. G., \& da Silva, R. P. (2010). Um modelo de cores na usabilidade das interfaces computacionais para os deficientes de baixa visão. Design e Tecnologia, 1(01), 66-78. doi: 10.23972/det2010iss01pp66-78

Lima, E. (2018). O aluno com deficiência visual. Fundação DorinaNowill para Cegos. 52 p.

Leborg, C. (2015). Gramática visual. São Paulo: Gustavo Gilli.

Lupton, E., \& Phillips, J. C. (2008) Novos fundamentos do design. São Paulo: Cosac Naify.

Lupton, E. (2014). Type on screen: a critical guide for designers, writers, developers, and students. New York: Princeton Architectural Press.

Gil, M. (2000). Deficiência visual. Cadernos da TV Escola. Brasília: MEC. Secretaria de Educação a Distância. Recuperado de http://portal.mec.gov.br/seed/arquivos/pdf/deficienciavisual.pdf

MEC. (2008). Política Nacional de Educação Especial na Perspectiva da Educação Inclusiva. Recuperado de http://portal.mec.gov.br/index.php?option=com_docman\&view=download\&alias=16690politica-nacional-de-educacao-especial-na-perspectiva-da-educacao-inclusiva$05122014 \&$ Itemid $=30192$ 
Petterson, R. (2002). Information Design, An introduction. Amsterdam/Philadelphia: John Benjamins Publishing Company.

Piñero, D. M. C., Quero, F. O., \& Díaz, F. R. (2003). O Sistema Braille. Deficiência Visual: Aspectos Psicoevolutivos e Educativos. São Paulo: Santos Editora.

Samara, T. (2014). Design Elements: A Graphic Style Manual: Understanding the Rules and Knowing When to Break Them. Beverly: RockportPublishers.

Sociedade Brasileira de Visão Subnormal (SBVSN) (2010). I Consenso da Sociedade Brasileira de Visão Subnormal. -- São Paulo: Sociedade Brasileira de Visão Subnormal. Recuperado de http://visaosubnormal.org.br/downloads/completo\%20II\%20-\%20consenso\%202010.pdf

Sociedade Brasileira de Design da Informação (SBDI). (2020). Brasil. Recuperado de http://www.sbdi.org.br/definicoes

UKAAF. (2012). Creating clear print and large print documents: Guidance from UKAAF. UK Association for Accessible Formats. Recuperado de https://www.pat.nhs.uk/working-forus/Equality/Resources/UKAAF\%20creating\%20clear\%20print\%20and\%20large\%20print\%20 documents.pdf.

VisockyO'Grady, J., \&Visocky O'Grady, K. A. (2017). Designer's Research Manual. Second Edition. Massachessetts: Rockport.

Wong, W. (1998). Princípios de forma e desenho. São Paulo: Martins Fontes.

World Health Organization (WHO), \&The World Bank. (2012). Relatório mundial sobre a deficiência; tradução Lexicus Serviços Lingüísticos. - São Paulo SEDPcD. 334 p.

\section{Sobre o(a/s) autor(a/es)}

Juliana Bueno, Dra., UFPR, Brasil <julianabueno.ufpr@gmail.com>

Caroline Rodrigues de Lima, Graduanda, UFPR, Brasil <carolinerlima625@gmail.com>

Karina de Abreu Antoniolli, Graduanda, UFPR, Brasil <antoniolli.kari@gmail.com> 